\title{
Economic valuation of water supply service from two community forests in Palpa district
}

\author{
Y. Khanal ${ }^{1}$, C.P. Upadhyaya ${ }^{2}$ and R.P. Sharma ${ }^{3}$
}

\begin{abstract}
Apart from physical products, community forests (CF) in Nepal generate various ecosystem services that could be important not only to the stakeholders at local level, but also to the stakeholders at the regional and the global levels. Water supply from CF would be one of the many ecosystem services whose benefits are provided to the stakeholders. Considering the economic importance of water supply service from CF, this study aims to assess the economic value of the water supply as a service from two CFs and also identify the factors affecting an individual's willingness to pay (WTP). Contingent valuation method was applied to evaluate the water supply service based on the information of users' WTP. Data from 74 households $(\mathrm{HH})$ in Lipindevi Thulopakho and Jarneldhara CFs in Palpa district (surveyed during May-June, 2008) were used. Results indicated that the mean WTP of Lipindevi Thulopakho and Jarneldhara CF users were US $\$ 36.62$ and $25.62 \mathrm{HH}^{-}$ ${ }^{1} \mathrm{yr}^{-1}$, respectively. The economic value of water supply service from Lipindevi Thulopakho and Jarneldhara CF were US\$ $93.54 \mathrm{ha}^{-1} \mathrm{yr}^{-1}$ and $134.06 \mathrm{ha}^{-1} \mathrm{yr}^{-1}$, respectively. Factors like distance of the house from water source, daily water consumption, wealth status and caste were associated with substantial influences on an individual's WTP. This study concludes that there would be a high possibility for generating extra income with the development of a payment mechanism for water supply service from CF.
\end{abstract}

Key words: Community forest, contingent valuation, economic valuation, water supply, willingness to pay

$\mathbf{M}$ ost of the accessible forests in mid hills of Nepal have been handed over to the local communities for protection, management and utilization in the form of community forests (CF). The CF provide multiple goods (e.g., timber, fuel wood, fodder/grass, leaf litter, and many non timber forest products) as livelihood sustenance for the local people, and also help support the national economy. $\mathrm{CF}$ also provide various ecosystem services such as watershed protection, biodiversity conservation, carbon storage and many others. These services could be of local, national, or even global importance, and have, therefore, been accorded due attention not only by local and regional communities, but also by the global communities over the recent years (Powell, et al., 2002; Scherr, et al., 2004).

Forests have major effects on hydrological processes, although the extent and value of these services vary with individual watershed circumstances. The major hydrological services of the forests include quantity and quality of water supply, flow regulation and aquatic productivity Johnson, et al., 2001; Powell, et al., 2002). Forests play an important role in global hydrological cycle; help stimulate rainfall, protect soils from erosion (Echavarria, et al., 2005) and maintain water quality and stable water flow. Forests store appreciably more water than agricultural soils or cleared land (Kaiser and Roumasset, 1999).

CF play an important role in supplying water to the rural households in the mid hills of Nepal. However, this role (service) has rarely been estimated in monetary terms (Hermans, et al., 2005). Therefore, proper identification and valuation of these roles are necessary to convince decision makers about the importance of managing upper catchments as a part of water supply reservoir. Assessments have to be done to value the water for different uses (household consumption, irrigation, hydropower) and for different users (Karna, 2008), so that the service providers can receive compensation from the service users.

Planners and decision-makers usually consider the easily quantifiable, material-product, forest benefits

\footnotetext{
Asst. Forest Officer, Far-Western Regional Forest Directorate, Dhangadhi, Email: yajnamurti@hotmail.com

Professor, Institute of Forestry, Pokhara

Research Fellow, Norwegian University of Life Sciences (UMB), Norway
} 
that could be traded in the markets. This creates a condition whereby intangible, environmental benefits from forests have been ignored and the total services provided by the forestry sector were underestimated. This has led to the under-valuation of forests and natural resources (Niraula, 2004). The economic value of water supply services is important to policy makers, and planners for better planning and accounting of the inherent value of forest resources. Under financial constraints, the governments often resort to curtailing conservation allocations from public investment funds for conserving and preserving the natural environment (Kulshreshtha, et al., 2003). This may be a result of lack of information on the monetary worth of these intangible, environmental services. This study has been conducted to fill out a part of this knowledge gap.

Valuation of water supply service presents an opportunity to promote public awareness on the importance of forests for human well being and to provide an economic incentive for forest owners to own and manage forest resources sustainably. It also encourages ecological restoration and inspires individual efforts to reduce consumption of natural resources and minimize human impacts on ecosystems.

This study has addressed the following objectives:

$>$ to assess economic value of domestic water supply service of the community forests, and

$>$ to identify the factors affecting individual's willingness to pay (WTP).

\section{Materials and methods}

\section{Study area}

The study was carried out in Palpa district, a part of the mid hill region of Nepal (Figure 1). Most of the forests in this district have been handed over to local users as CF. Out of the 528 CFs (DFO records 2008); two CFs were selected on specific criteria and consultation with DFO staff. The chief criterion used was whether the CF was supplying water to at least 30 households (household may or not be users of that CFUG). Similarly, the other criterion was the proximity of the CF to a nearby local market, so the water users could easily express monetarily, their WTP for the value of water supply service.

Lipindevi Thulopakho CF is located in Tansen Municipality-13 whereas Jarneldhara CF is in

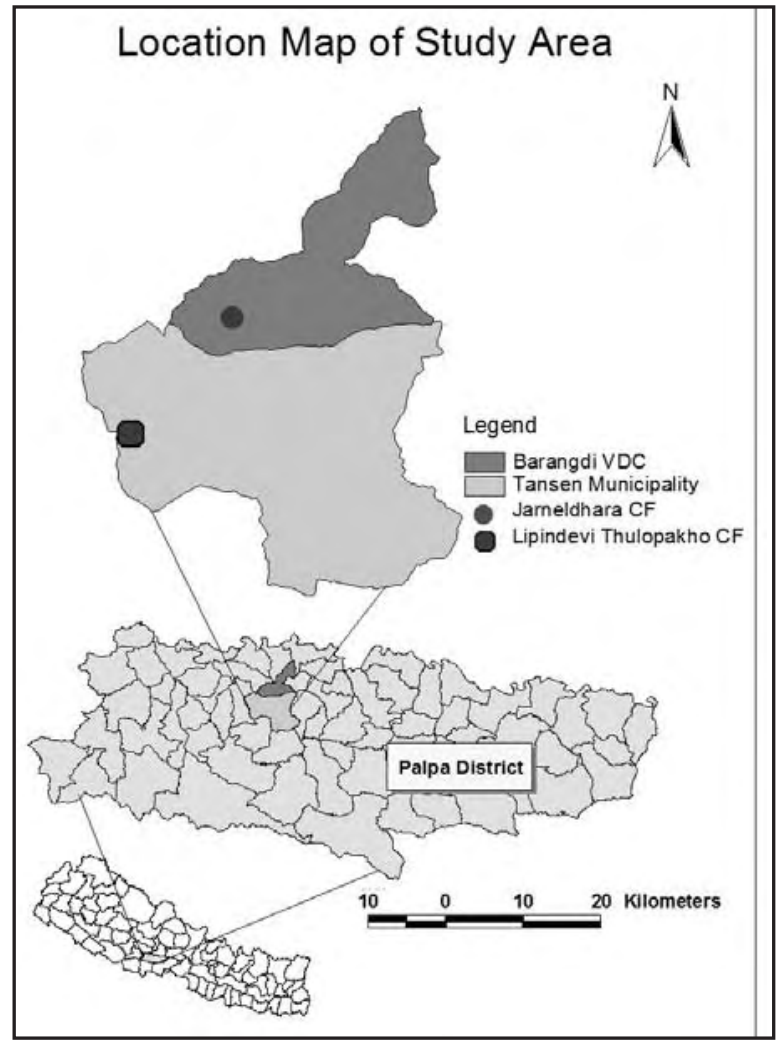

Fig 1 : Study area

Barangdi VDC Ward number 3 (Figure 1). The area of Lipindevi Thulopakho CF was 26.23 ha with 158 user households whereas the area of Jarneldhara CF was 8.6 ha with 58 user households. Both CF areas were situated on moderate to steep slopes with altitudes ranging from 1100-1400 m above sea level. Jarneldhara CF was mostly situated on the northern aspect whereas Lipindevi Thulopakho flanked the north-eastern aspect. The soil type varied from sandy loam to clay loam and was mostly brown in color. The average maximum and minimum temperatures of the district were $23^{\circ} \mathrm{C}$ and $14^{\circ} \mathrm{C}$, with a mean annual rainfall of $1903 \mathrm{~mm}$ (DFO-Palpa, 2007). Lipindevi Thulopakho CF consisted mainly of natural SchimaCastanopsis forest with some scattered plantations of Pinus roxburghii whereas Jarneldhara CF mainly consisted of natural Schima-Castanopsis forest.

\section{Contingent valuation}

This study applied Contingent Valuation Method (CVM), a form of "stated preference method". CVM allows people who benefit from a particular resource to convey to the researchers directly through surveys, what they are willing to pay for the environmental services or some improvement in environmental quality (Richards, et al., 2003; Chaudhry, et al., 2007). It is also used for measuring the WTP for public projects designed to provide services such as safe 
drinking water and sanitation (Ojeda, et al., 2007). One of the strengths of this method is that it can capture both the use value (e.g., drinking water use) and non-use value (protection of threatened aquatic species) (Mitchell \& Carson, 1993). The current trend in CVM is towards the referendum formats using the dichotomous choice method (Whittington, 2002). Bidding game approach has also been used for bid collection.

This study used the open-ended questionnaire survey approach to elicit the willingness to pay. This is the most common and simplest form of CVM (Freeman III, 2003). There are two main reasons for this choice. Firstly, dichotomous choice questions tend to overestimate the WTP, especially for studies conducted in low-income countries (White and Lovett, 1999). Secondly, getting statistically reliable results from a dichotomous choice type of survey requires a large sample (White and Lovett, 1999), not possible in the current study due to the population size, time and resource constraints.

During the questionnaire survey, the form and frequency of payments were clearly explained to the respondents. The payment vehicle in this study was the annual membership fee for the water users from the particular CF to maintain at least the quality and quantity of water as it is. A strong criticism of CVM has been that answers obtained from surveys relying upon hypothetical propositions were subject to a variety of biases (Diamond \& Hausman, 1994; Baral et al., 2008). The primary sources of biases include hypothetical bias, information bias, strategic bias, design bias and embedding bias (Mitchell and Carson, 1993; Hanley, et al., 2004; Poudel and Johnsen, 2008). This study was designed to reduce such potential biases by delivering clear and equal information to all the respondents, explaining a well-defined payment vehicle and using a thoroughly pre-tested questionnaire. To test the validity of the responses, the questionnaire contained questions about the respondents' demographic and socio-economic backgrounds as well.

\section{Sampling}

Initially, all the households (HHs) using the forest as a water source were identified by informal discussions with the forest users committees. Among the total $\mathrm{HHs}, 65$ and $45 \mathrm{HHs}$ were identified as water-users HHs in Lipindevi Thulopakho and Jarneldhara CFUGs, respectively. Then 40 and $34 \mathrm{HHs}$ from
Lipindevi Thulopakho and Jarneldhara CFUGs were purposively selected to represent all the socioeconomic groups (i.e. wealth status and caste) and locations (hamlets). As each $\mathrm{HH}$ represented a sampling unit, one of the $\mathrm{HH}$ members taking decisions on economic activities was identified for survey. Out of the 40 respondents identified for Lipindevi Thulopakho CFUG, 28 were male and 12 were female. Similarly, out of the 34 respondents identified for Jarneldhara CFUG, 22 were male and 12 were female.

\section{Data analysis}

The individual WTP bid for water supply service from the $\mathrm{CF}$ were acquired from the questionnaire survey. The WTP bids were then fed to the Statistical Program for Social Sciences (SPSS) for further analysis. Based on individual WTP bids, the mean WTP and the total WTP for each CFUG were computed. The total WTP value of each CFUG was divided by the $\mathrm{CF}$ area to arrive at a per hectare value of each $\mathrm{CF}$.

The WTP bid was modeled as a function of different potential, explanatory variables (age, sex, education, caste, wealth status, HH size, landholdings, livestock unit, daily water consumption, house distance from water source). For this, multiple linear regression model of the following form was used:

$$
\begin{aligned}
\mathrm{WTP}= & \beta_{0}+\beta_{1} \mathrm{X}_{1}+\beta_{2} \mathrm{X}_{2}+\beta_{3} \mathrm{X}_{3}+\ldots+ \\
& \beta_{\mathrm{n}} \mathrm{X}_{\mathrm{n}}+\varepsilon_{i}
\end{aligned}
$$

where, WTP is the users' willingness to pay for water supply services (dependent variable), $\beta_{0}-\beta_{\mathrm{n}} \beta_{0}-\beta_{\mathrm{n}}$ were the parameters to be estimated, $\mathrm{X}_{1}-\mathrm{X}_{\mathrm{n}}=$ explanatory variables influencing WTP and $\varepsilon_{i}=$ random error normally and independently distributed with zero mean and constant variance of one.

\section{Results and discussion}

\section{Characteristics of the respondents and their households}

The mean age of the 74 respondents was 46 years and they were nearly evenly distributed between males and females. The household member mostly taking decisions on economic activities was identified as the respondent and the majority of these were male. About a third $(32 \%)$ of the respondents had education up to secondary school level and very few $(\sim 9 \%)$ were illiterate. Two-thirds of the respondents 
belonged to the medium wealth class. The average family size of the respondents was 6.1 , which was higher than the district as well as national average (ISRC, 2007). The mean land holding size of respondents significantly differed with their wealth status $(\mathrm{p}<0.05)$. The overall mean landholding size per household was 0.78 ha which was slightly higher than the district average of 0.71 ha (ISRC, 2007) and lower than the national average of 0.96 ha (CBS, 2003). The average consumption of water per household per day was 253 liters and the average one way walking time from the respondents' house to the water source was 18 minutes (Table 1 ).

Table 1: Characteristics of respondents $(n=74)$

\begin{tabular}{ll}
\hline Age (years; mean, SD) & $46(7.39)$ \\
Gender (n, \%) & \\
$\quad$ Male & $50(67.6)$ \\
$\quad$ Female & $24(32.4)$ \\
Education of the respondents (n, \%) & \\
$\quad$ Illiterate & $7(9.45)$ \\
$\quad$ Primary & $13(17.56)$ \\
$\quad$ Lower secondary & $19(25.67)$ \\
$\quad$ Secondary & $24(32.43)$ \\
$\quad$ College education & $11(14.86)$ \\
Wealth status (n, \%) & \\
$\quad$ Rich & $17(22.9)$ \\
$\quad$ Medium & $49(66.2)$ \\
$\quad$ Poor & $8(10.8)$ \\
Ethnicity (n, \%) & $8(10.8)$ \\
$\quad$ Brahmin & $45(60.8)$ \\
$\quad$ Chhetri & $21(28.4)$ \\
$\quad$ Magar & $6.1(2.47)$ \\
Household size (mean, SD) & $0.78(0.44)$ \\
Landholdings (hectares; mean, SD) & $2.75(1.59)$ \\
Livestock holding (LSU; mean, SD) & $253(69.18)$ \\
Daily water consumption (litre; mean, SD) \\
House distance from water source (average \\
one way walking time in minute; mean, SD) & $18(10.6)$ \\
\hline SD Stard &
\end{tabular}

$\mathrm{SD}=$ Standard deviation, LSU $=$ Livestock Unit

Where, $1 \mathrm{LSU}=1$ buffalo $=1.2 \mathrm{cow}=4$ goats $=5$ sheep $=2$ calves (Thapa and Poudel, 2000).

\section{Mean WTP}

The mean annual WTP value of the different category of respondents for the water supply service is shown in Table 2. The mean WTP values of the rich, medium and poor were significantly different in both the CFUGs $(\mathrm{p}<0.05)$. LSD $\mathrm{D}_{0.05}$ test indicated that only the mean WTP values of the rich and medium were significantly higher than the poor in Lipindevi Thulopakho CFUG whereas the rich, medium and poor all differed significantly in Jarneldhara CFUG. However, there was no significant difference between the mean WTP values of male and female in both CFUGs ( $\mathrm{p}>0.05)$.

Table 2 : Mean annual WTP per household for domestic water supply services from $\mathrm{CF}$

\begin{tabular}{|c|c|c|c|}
\hline Name of CF & Cate & & $\begin{array}{c}\text { Mean WTP hh-1 } \\
\text { (US\$)* }\end{array}$ \\
\hline \multirow{6}{*}{$\begin{array}{l}\text { Lipindevi } \\
\text { Thulopakho }\end{array}$} & \multirow{3}{*}{ Wealth status } & Rich & 41.19 (11.32) \\
\hline & & Medium & $36.13(4.67)$ \\
\hline & & Poor & $30.92(4.36)$ \\
\hline & \multirow{2}{*}{ Sex } & Male & $36.29(5.67)$ \\
\hline & & Female & $37.38(9.38)$ \\
\hline & Mean & & $36.62(6.88)$ \\
\hline \multirow{6}{*}{ Jarneldhara } & \multirow{3}{*}{ Wealth status } & Rich & $30.15(3.32)$ \\
\hline & & Medium & $25.49(3.43)$ \\
\hline & & Poor & $16.15(5.91)$ \\
\hline & \multirow{2}{*}{ Sex } & Male & $26.51(4.71)$ \\
\hline & & Female & $24.00(6.44)$ \\
\hline & Mean & & $25.62(5.43)$ \\
\hline
\end{tabular}

The total economic value of Lipindevi Thulopakho community forest based on WTP came to US\$ $2453.54 \mathrm{yr}^{-1}$, which is equivalent to US\$ $93.54 \mathrm{ha}^{-1}$ $\mathrm{yr}^{-1}$. Similarly, the total economic value of Jarneldhara community forest totalled to US\$ $1152.9 \mathrm{yr}^{-1}$ which is equivalent to US\$ $134.06 \mathrm{ha}^{-1} \mathrm{yr}^{-1}$. Although the average WTP value of Lipindevi Thulopakho CF was high, its per unit area value was low because of the proportion of water source and the water users with forest area was low.

These results were comparable to studies of similar types (Reyes, et al., 2002 in Costa Rica) where they had focused on hydropower and domestic consumption, and found the value of water supply as US\$ $137 \mathrm{ha}^{-1} \mathrm{yr}^{-1}$ based on replacement and maintenance costs.

\section{Factors influencing WTP}

The WTP [see model form in (1)] was regressed against all potential explanatory variables (full model), and variables with non-significant estimates $(\mathrm{p}>0.05)$ were excluded. Then, the W'TP was regressed against the remaining variables (reduced model). Table 3 presents parameter estimates and fit statistics. The best reduced model explained $56 \%$ of the total variability of WTP, indicating that the estimated model was fairly satisfactory. Multi-collinearity problem among independent variables was not 
Table 3 : The parameter estimates and fit statistics of the full and the reduced model with possible explanatory variables for determining individual's WTP [model form used is presented in (1)]

\begin{tabular}{|c|c|c|c|c|c|}
\hline \multirow{2}{*}{ Explanatory variables } & \multicolumn{2}{|c|}{ Full model } & \multicolumn{2}{|c|}{ Reduced model } & \multirow{2}{*}{$\begin{array}{c}\text { Pearson } \\
\text { correlation } \\
\text { coefficient }(r)\end{array}$} \\
\hline & $\begin{array}{r}\text { Parameter } \\
\text { estimates }\end{array}$ & VIF & $\begin{array}{l}\text { Parameter } \\
\text { estimates }\end{array}$ & VIF & \\
\hline Constant & $16.662^{*}$ & - & $17.928^{*}$ & - & - \\
\hline Age of the respondent & 0.062 & 1.362 & - & - & 0.096 \\
\hline Education of respondent & -0.052 & 1.938 & - & - & 0.253 \\
\hline Household size & -0.098 & 2.295 & - & - & 0.156 \\
\hline Livestock unit & -0.011 & 1.457 & - & - & 0.054 \\
\hline Landholdings & 2.780 & 1.375 & - & - & 0.289 \\
\hline House distance from water source & $-0.277 *$ & 1.665 & $-0.233^{*}$ & 1.433 & - 0.484* \\
\hline Daily consumption & $0.043^{*}$ & 2.045 & $0.049 *$ & 1.036 & $0.511 *$ \\
\hline Sex (dummy, female $=1)$ & -0.296 & 1.463 & - & - & -0.074 \\
\hline Wealth status (dummy, Rich =1) & $5.330^{*}$ & 1.208 & $5.834^{*}$ & 1.029 & 0.250 \\
\hline Ethnicity (dummy, Brahmin/Chhetri = 1) & $5.208^{*}$ & 1.882 & $5.748^{*}$ & 1.402 & $0.504^{*}$ \\
\hline Model summary & \multicolumn{2}{|c|}{$\begin{array}{c}\text { Adj. } \mathrm{R}^{2}=0.543, \\
\mathrm{RMSE}=5.62, n=74\end{array}$} & \multicolumn{2}{|c|}{$\begin{array}{c}\text { Adj. } \mathrm{R}^{2}=0.559, \\
\mathrm{R} M S E=5.52, n=74\end{array}$} & \\
\hline
\end{tabular}

serious as variance influence factor (VIF) was less than 10 (Montgomery et al., 2001). Most of the explanatory variables were not significant $(\mathrm{p}>0.05)$ but higher WTP bids were significantly associated with more daily water consumption while the users further from the water source had less WTP. Wealth and caste status of the respondents also displayed significant influence on the individual's WTP. Education of the respondent, household size, livestock unit and landholdings were positively correlated with WTP; however, they were not significant.

Water users who were nearer to the water source were willing to pay more because the next best alternative for them would have been very far from their dwelling and, therefore, would cost high. On the other hand, the users who were very far from the current water source were willing to pay less because they could opt for the next best alternative with little extra cost. Those users whose daily consumption of water was high were willing to pay more because they would have to bear higher extra cost to use the next best alternative. Similarly categorical variables like ethnicity and wealth status influenced the WTP but sex did not. None of the aforementioned significant parameters are surprising.

\section{Conclusion and implication}

This study illustrated a promising economic value of water supply from CF. On average the water users were willing to pay US $\$ 36.62$ and 25.62 per household for Lipindevi Thulopakho and Jarneldhara CFUG, respectively. This suggests a possibility of generating extra income for CFUG with the development of a payment mechanism. The users, who lived nearer to the water source and consumed more water, were willing to pay higher amounts for water supply services from the CF. Similarly, people belonging to rich and Brahmin/Chhetri groups were also willing to pay higher amounts.

The economic values are useful for the analysis of costs and benefits and for making appropriate decision for the conservation of natural resources. This study may help raise public and political awareness on the importance of CF, and help policymakers formulate appropriate green-economic policy.

\section{Acknowledgement}

This paper is an output from a part of M. Sc. (Forestry) thesis. The study was conducted with a research grant from Community Based Forest and Tree Management in the Himalaya (COMForM), Institute of Forestry, Pokhara, Nepal.

\section{References}

Baral, N., Stern, M.J. and Bhattarai, R. 2008. Contingent valuation of ecotourism in Annapurna conservation area, Nepal: Implications for sustainable park finance and local development. Ecological Economics, (doi: 10.1016/ j.ecolecon.2008.02.004). 
CBS. 2003. Population Census 2001. Central Bureau of Statistics, Kathmandu.

Chaudhry, P., Singh, B. and Tewari, V.P. 2007. Nonmarket economic valuation in developing countries: Role of participant observation method in CVM analysis. Journal of Forest Economics, 13: 259-279.

DFO-Palpa. 2007. District wise community forest monitoring report 2063/64. District Forest Office Palpa, Tansen.

Diamond, P.A. and Hausman, J.A. 1994. Contingent valuation: is some number better than no number? Journal of Economic Perspectives, 8 (4): 45-64.

Echavarria, M., Vogel, J., Alban, M. and Meneses, F. 2005. Protecting forests can improve water management. id21 natural resources highlights: Water, $1-1$.

Freeman III, A.M. 2003. The Measurement of Environmental and Resource Values: Theory and Methods. Second edition. Resources for the Future, Washington DC.

Hanley, N., Shogren, J.F. and White, B. 2004. Environmental Economics in Theory and Practice. Reprint editon. Macmillan India Ltd, New Delhi.

Hermans, L., Halsema, G. and Renault, D. 2005. Developing economic arrangements for water resources management: The potential of stakeholder oriented water valuation. OECD Workshop on Agriculture and Water: Sustainability, Markets and Policies. South Australia: http://www.oecd.org/agr/env.

ISRC. 2007. District Profile of Nepal. Intensive Study and Research Centre, Kathmandu.

Johnson, N., White, A. and Perrot-Maitre, D. 2001. Developing Markets for Water Services from Forests: Issues and Lessons for Innovators. Forest Trends with World Resource Institute and the Katoomba Group, Washington DC.

Kaiser, B. and Roumasset, J. 1999. Water Management and the Valuation of Indirect Environmental Services. Working Paper No. 995. University of Hawaii.

Karna, P.K. 2008. Making payment for environmental services work: A case study of Shivapuri National Park, Nepal. In Shifting Paradigms in Protected Area Management (eds.) Bajracharya, S. B. and Dahal, N. National Trust for Nature Conservation, Kathmandu, 171-185.

Kulshreshtha, S.N., Johnston, M. and Lac, S. 2003. Value of carbon sequestration in protected areas: A case study of Saskatchewan Provincial Parks. Prairie Forum, 28 (2): 127-143.

Mitchell, R.C. and Carson, R.T. 1993. The value of clean water: The public's willingness to pay for
Boatable, Fishable and Swimmable quality water. Water Resources Research, 29 (7): 2445-2454.

Montgomery, D.C., Peck, E.A. and Vining, G.G. 2001. Introduction to linear regression analysis. Third edition. Wiley, NewYork.

Niraula, D.R. 2004. Integrating total economic value for enhancing sustainable management of community forests: A forward looking approach. In Twenty Five Years of Community Forestry (eds.) Kanel, K. R.; Mathema, P.; Kandel, P. R.; Niraula, D. R.; Sharma, A. R. and Gautam, M. Proceeding of the Fourth National Workshop on Community Forestry, Community Forest Division, Department of Forest, Kathmandu, 48-55.

Ojeda, M.I.; Mayer, A.S. and Solomon, B.D. 2007. Economic valuation of environmental services sustained by water flows in the Yaqui River Delta. Ecological Economics (doi:10.1016/j.ecolecon. 2007.06.006).

Poudel, D. and Johnsen, F.H. 2008. Valuation of crop genetic resources in Kaski, Nepal: Farmer's willingness to pay for rice land races conservation. Journal of Environmental Management,(doi: 10.1016/ j.jenvman.2007.12.020).

Powell, I.; White, A. and Landell-Mills, N. 2002. Developing Markets for the Ecosystem Services of Forests. Forest Trends, Washington DC.

Reyes, V., Segura, O. and Verweij, P. 2002. Valuation of Hydrological Services Provided by Forests in Costa Rica. In Understanding and Capturing the Multiple Values of Tropical Forests (ed.) Verweij, P. World Bank and WWF, Wageningen, the Netherlands,101-106.

Richards, M., Davies, J. and Yaron, G. 2003. Stakeholder Incentives in Participatory Forest Management: A Manual for Economic Analysis. ITDG Publishing, London, UK.

Scherr, S., White, A. and Khare, A. 2004. New Finance for Tropical Forests: The Emerging Markets for Ecosystem Services from Forests. Forest Trends, Washington DC.

Thapa, G.B. and Poudel, G.S. 2000. Evaluation of the livestock carrying capacity of land resources in the hills of Nepal based on total digestive nutrient analysis. Agriculture, Ecosystem and Environment, 78: 223-235.

White, P.C. and Lovett, J.C. 1999. Public preference and willingness to pay for nature conservation in the North York Moors National Park, UK. Journal of Environmental Management, 55: 1-33.

Whittington, D. 2002. Improving the performance of contingent valuation studies in developing countries. Environmental and Resource Economics, 22: 323-367. 